\title{
THE MODELLING OF TEMPERATURE-DEPENDENT STRESS- -STRAIN CURVES FOR WELDABLE STEELS
}

\author{
Jerzy Winczek ${ }^{1}$, Miloš Mičian ${ }^{2}$, Vitalii Ivanov ${ }^{3}$ \\ ${ }^{I}$ Institute of Mechanical Technology, Czestochowa University of Technology \\ Częstochowa, Poland \\ ${ }^{2}$ Department of Technological Engineering, University of Žilina \\ Žilina, Slovakia \\ ${ }^{3}$ Department of Manufacturing Engineering, Machines and Tools, Sumy State University \\ Sumy, Ukraine \\ winczek@imipkm.pcz.czest.pl,milos.mician@fstroj.uniza.sk,ivanov@tmvi.sumdu.edu.ua
}

Received: 7 August 2018; Accepted: 26 September 2018

\begin{abstract}
The calculation of stresses in the steel elements subjected to the thermomechanical loads requires taking into account the influence of temperature on mechanical properties of a material, including the stress-strain curve. The simplified and extended computational models of temperature-dependent tensile curves have been discussed. The methodology of the stress-strain curve construction in the entire temperature range of the solid state of the material has been proposed. The considerations are illustrated by the examples of calculated stress-strain curves in different temperatures for S235 and S355 welding steels.
\end{abstract}

MSC 2010: 74A10, 74C05, 74D10, 74F05

Keywords: modelling, thermomechanics, stress-strain curve

\section{Introduction}

In the thermomechanical states calculation of constructions and machine parts made from metals, their alloys and composite materials, the mechanical properties of the material depending on temperature, including tensile (compression) curves, are used [1-5]. These properties are determined based on the results of a static tensile test performed at different temperatures. In this area, intensive research of mechanical properties of steel are carried out [6-8], also due to their resistance to fire [9].

\section{Modelling of the stress-strain curve}

Stress-strain dependencies can be defined in the form of curve points (Fig. 1) $[8,10]$. Often, other parameters of the tensile curve as a function of temperature are 
used, such as the longitudinal modulus (Young modulus) E, strain hardening modulus, yield stress $\sigma_{0}$ and tensile strength TS. In the elastic range $\left(\sigma<\sigma_{0}\right)$, the stress-strain function is described in accordance with Hooke's law:

$$
\sigma(\varepsilon, T)=E(T) \varepsilon
$$

where: $\sigma$ - stress value of tension curve, $\varepsilon$ - strain, $T$ - temperature, $\sigma_{0}$ - yield stress, $E$ - Young modulus.

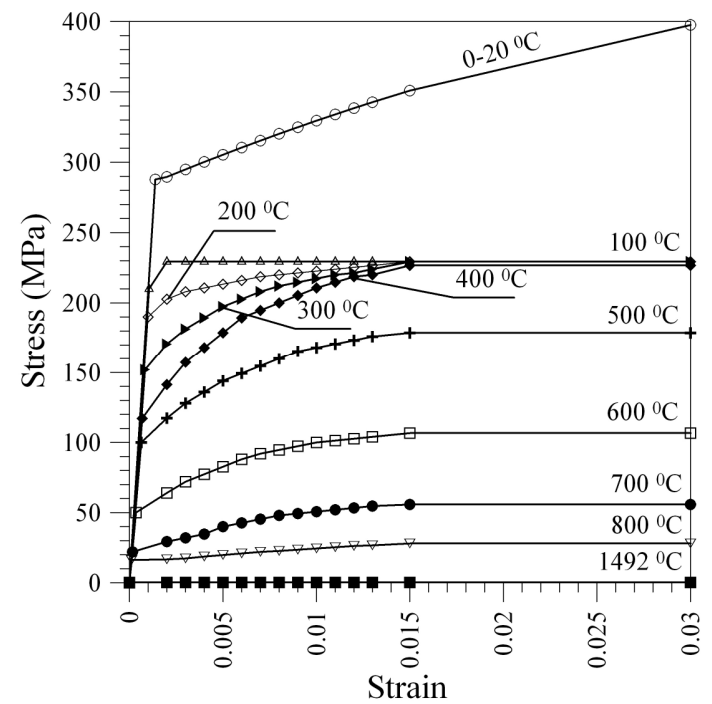

Fig. 1. Tensile curves depending on the temperature for S235 steel [10]

In the elastic-plastic range, the tensile curve is described by a function or by a strain hardening modulus. The strain hardening functions were the subject of researchers' interest in the first half of the 20th century. Ludwik [11] began a modelling of the stress-strain curve and described it with following function:

$$
\sigma=\sigma_{0}+K_{L} \varepsilon^{n_{L}}
$$

where $\sigma$ represents stress, $\sigma_{0}$ yield stress, $\varepsilon$ plastic strain, $K_{L}$ and $n_{L}$ are the experimentally determined parameters. In turn, Hollomon $[12,13]$ suggested a function:

$$
\sigma=K_{H} \varepsilon^{n_{H}}
$$

Swift [14] regarding Hollomon's law introduced the constant into the strain term:

$$
\varepsilon=\varepsilon_{0}+K_{S} \sigma^{n_{S}} \text { or } \sigma=K_{S}^{\prime}\left(\varepsilon+\varepsilon_{0}\right)^{n_{S}^{\prime}}
$$

where $\varepsilon_{0}, K_{S}, K_{S}{ }_{S}, n_{S}$ and $n_{S}^{\prime}$ are the parameters. 
The function generating the tensile curves can be described in the form:

$$
\sigma(\varepsilon, T)=\sigma_{o}(T)+\sigma_{s h}\left(\varepsilon-\varepsilon_{0}, T\right)
$$

where: $\sigma_{0}$ - limit of elasticity or yield stress, $\sigma_{s h}$ - strain hardening function, $\varepsilon_{0}$ - the strain corresponding to yield stress $\sigma_{0}$ determined by the dependence:

$$
\varepsilon_{0}(T)=\frac{\sigma_{o}(T)}{E(T)}
$$

When using the strain hardening modulus, which is the tangent of the angle of inclination of the function to the axis $\varepsilon$ (Fig. 2a), this module is defined as follows:

$$
\sigma_{s h}(T)=\frac{T S(T)-\sigma_{0}(T)}{\varepsilon_{\max }(T)-\varepsilon_{0}(T)}
$$

In the case of elastic - ideal plastic material $\sigma_{s h}(T)=0$, the tensile curve is straight parallel to the axis $\varepsilon$ (Fig. 2b).

a)

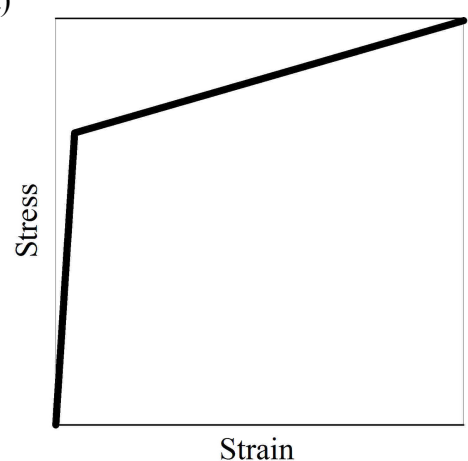

b)

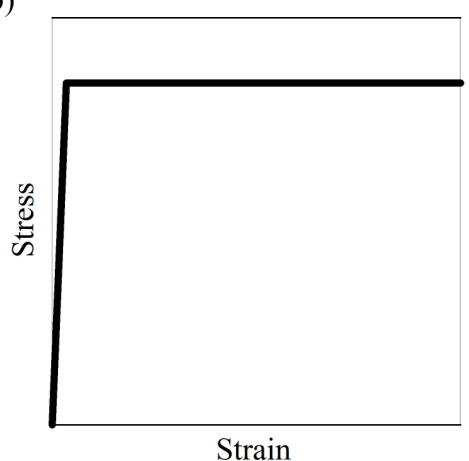

Fig. 2. Stress-strain curves: a) with strengthening, b) without strengthening

The calculation of stress as a function of strain and temperature first requires the determination of stress-strain curve points for a given temperature $T$ or its parameters: Young modulus $E(T)$, strain hardening modulus, yield stress $\sigma_{0}(T)$ and tensile strength $S T(T)$ or ultimate tensile strength $U S T(T)$. The searched curve can be determined based on the curves defined for the temperatures closest to the considered temperature, meaning the determination of parameters of the stress-strain curve for temperature $T>T_{1}$ and $T<T_{2}$, where $T_{2}$ and $T_{1}$ denote temperatures for which the tensile curves are known (defined). In the case of curve description by the points, the searched curve at the desired temperature $T$ is calculated for individual points, using the proportionality principle, according to the relationship (Fig. 3):

$$
\sigma_{i}(T)=\sigma_{i}\left(T_{1}\right)+\frac{\sigma_{i}\left(T_{2}\right)-\sigma_{i}\left(T_{1}\right)}{T_{2}-T_{1}}\left(T-T_{1}\right)
$$




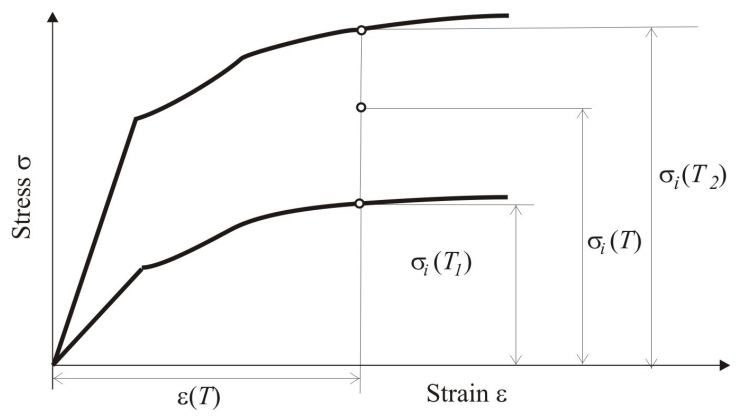

Fig. 3. Interpolation of stress-strain curve points

Regardless of the description method of the stress-strain curve, the stress values in the elastic range are determined analogously to the equation (1) according to Hooke's law:

$$
\sigma(\varepsilon, T)=E(T) \varepsilon
$$

In the elastic-plastic range, the stress value is determined depending on the description of the curve. In the case of the curve description by points, we start the calculation of strain values for strain $\varepsilon$ by determining the points of the curve $\varepsilon_{i}$ and $\varepsilon_{i+1}$ (Fig. 4), between which there are strain value $\varepsilon$. The stress value is calculated from the dependence:

$$
\sigma(\varepsilon, T)=\sigma_{i}\left(\varepsilon_{i}, T\right)+\frac{\sigma_{i+1}\left(\varepsilon_{i+1}, T\right)-\sigma_{i}\left(\varepsilon_{i}, T\right)}{\varepsilon_{i+1}-\varepsilon_{i}}\left(\varepsilon-\varepsilon_{i}\right)
$$

In the case of describing the strain hardening curve with the function, the stress value is determined in accordance with the formula:

$$
\sigma(\varepsilon, T)=\sigma_{o}(T)+\sigma_{s h}\left(\varepsilon-\varepsilon_{0}, T\right)
$$

In numerical methods, the dependencies $E=E(T)$ and $\sigma_{0}=\sigma_{0}(T)$ are often used. Figures 4 and 5 show diagrams of these relations for steel S235JR [15] and S355J2H [9].
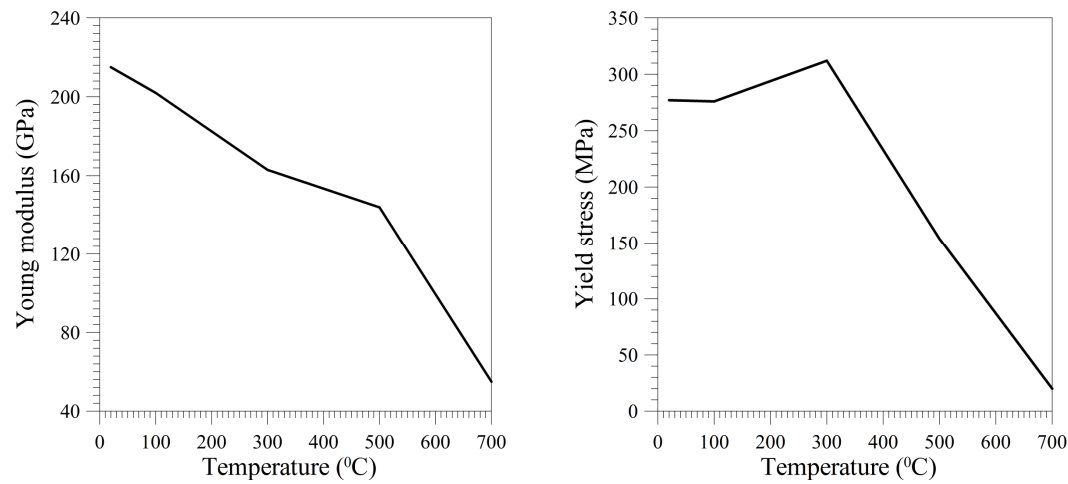

Fig. 4. Young's modulus and yield strength as a temperature function for S235JR steel 

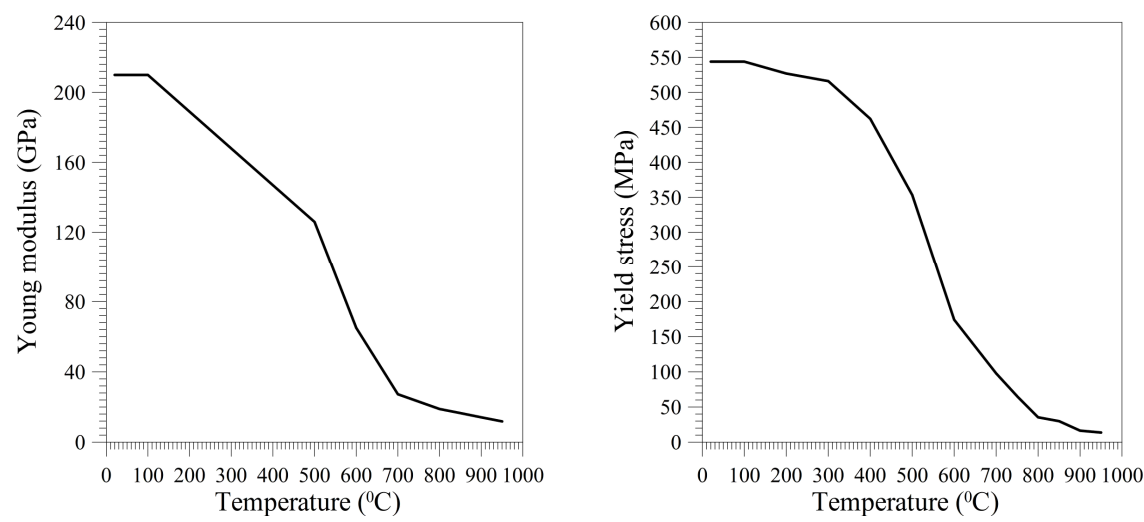

Fig. 5. Young's modulus and yield strength as a temperature function for $\mathrm{S} 355 \mathrm{~J} 2 \mathrm{H}$ steel

\section{Example of computations}

In the example of computations, the models of tensile curves of $\mathrm{S} 355 \mathrm{~J} 2 \mathrm{H}$ as a function of temperature based on the results of experimental studies contained in the research report Outinen et al. [6] is presented. The parameters of Swift's and Hollomon's equations were determined in [16]. The comparison of the stress-strain curves described by Swift and Hollomon laws for the temperature $500^{\circ} \mathrm{C}$ with the experimental results and the curves obtained by interpolation from $400^{\circ} \mathrm{C}$ and $600^{\circ} \mathrm{C}$ in Figure 6 is presented.

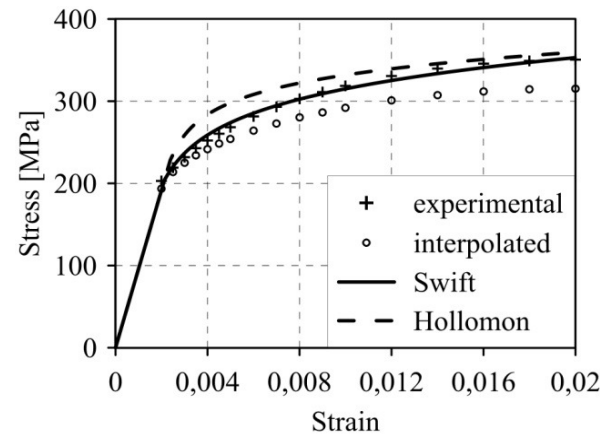

Fig. 6. The comparison of the stress-strain curves described by Swift and Hollomon laws for the temperature $500^{\circ} \mathrm{C}$ with the experimental results and the curves obtained by interpolation

\section{Conclusions}

The methods of determination of tensile (strain hardening) curves proposed in the work allow one to develop approximate strain-stress characteristics of steels 
at different temperatures. A verification of the correctness of developed models of strain-stress curves is difficult. Models developed with the methods described in the paper are difficult to consider as fully compatible with the real tensile curves, but are sufficiently suitable for use in the modeling of thermomechanical states of metals and their alloys. One of the indirect ways may be to compare the measured stresses in real elements with those calculated on the basis of the developed models.

\section{References}

[1] Kulawik, A., Sczygiol, N., \& Wróbel, J. (2016). Determination of stresses in the steel pipe during the superficial heat treatment process with helical path. Journal of Applied Mathematics and Computational Mechanics, 15(1), 79-86.

[2] Giżejowski, M.A., Szczerba, R.B., \& Gajewski, M.D. (2017). Resistance of mono-axially bent beams of welded I-sections FEM verification of Eurocode's buckling curve formulation, Proceedings of Eurosteel 2017, Ernst \& Sohn a Wiley Company, 1(2-3), 1265-1274, https://doi.org/10.1002/cepa.168.

[3] Węgrzyn-Skrzypczak, E., \& Skrzypczak T. (2017). Analytical and numerical solution of the heat conduction problem in the rod. Journal of Applied Mathematics and Computational Mechanics, 16(4), 79-86.

[4] Winczek, J., Makles, K., Gucwa, M., Gnatowska, R., \& Hatala, M. (2017). Modelling of strains during SAW surfacing taking into heat of the weld in temperature field description and phase transformations. IOP Conf. Series: Materials Science and Engineering, 225, 012038, DOI: 10.1088/1757-899X/225/1/012038.

[5] Murčinková, Z., Novák, P., Kompiš, V., \& Žmindák, M. (2018). Homogenization of the finitelength fibre composite materials by boundary meshless type method. Archive of Applied Mechanics, 88(5), 789-804, https://doi.org/10.1007/s00419-018-1342-5.

[6] Outinen, J., Kaitila, O., \& Mäkeläinen P. (2001). High-temperature testing of structural steel and modelling structure at fire temperatures. Research report. Helsinki Univeristy of Technology, Laboratory of Steel Structures, Publications 23, Espoo.

[7] Chen, J., Young, B., \& Uy, B. (2006). Behaviour of high strength structural steel at elevated temperatures. Journal of Structural Engineering, 1948-1954.

[8] Gawad, J., Szeliga, D., Bator, A., Pidvysockyy V., \& Pietrzyk M. (2004). Interpretation of the tensile test results interpretation based on two criterion optimization, In: Proc. 14. Conf. KomPlasTech, Informatics in Metal Technology, ed. M. Pietrzyk et al., Cracow, Akapit, 27-34.

[9] Outinen, J., \& Mäkeläinen, P. (2012). Mechanical properties of structural steel at elevated temperatures and after cooling down. Second Wokshop "Structures in Fire". Christchurch, 273-290.

[10] Winczek J. (2012). A simplified method of predicting stresses in surfaced steel rods. Journal of Materials Processing Technology, 212, 1080-1088.

[11] Ludwik, P. (1909). Elemente der Technologischen Mechanik. Berlin: Verlag von Julius Springer, 32 (http://www.bookprep.com/read/mdp.39015002016650).

[12] Hollomon, J.H. (1945). Tensile deformation. Transactions of the Metallurgical Society of AIME, $162,268-290$.

[13] Hollomon, J.H., \& Jaffe, L.D. (1945). Time-temperature relations in tempering steel. Transactions of the Metallurgical Society of AIME, 1381, 1-26. 
[14] Swift, H.W. (1952). Plastic instability under plane stress. Journal of the Mechanics and Physics of Solids, 1, 1-18.

[15] Skorwoński, W., Włóka, A., Chmiel, R. (2014). Modelling of strength properties of S235JR steel at increased temperature. Structure and Environment, 6(3), 32-37.

[16] Winczek, J., \& Ziobrowski, P. (2014). On the strain-hardening parameters of S355J2H steel considering the influence of temperature, In: Book of full texts of 20-th International Conference Engineering Mechanics 2014, May 12-15 Svratka, Czech Republik, 720-723. 